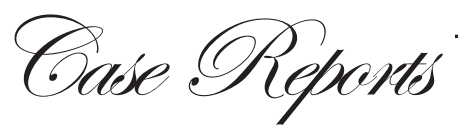

\section{Uneventful passage of long pointed foreign body after accidental ingestion: report of two unusual cases}

\section{Introduction}

Ingested sharp foreign objects have been known to cause serious complications involving visceral perforation, bleeding, obstruction, fistula formation and even object migration following perforation. ${ }^{1}$ Ingested foreign bodies tend to lodge at certain gastrointestinal locations: upper and lower oesophageal sphincters, pyloric canal, duodenum, ileocaecal valve and anus. The sites of perforation are usually at the ileum, appendix or colon. ${ }^{2}$

\section{Case report}

We report two unusual cases whereby two adult females, who were quilt makers by profession, had accidently ingested long sharp pointed needles about $8 \mathrm{~cm}$ long. Both the patients presented late to our emergency surgery department, after about 12-14 hours of ingestion of needles. As per history, one of the patients had accidently ingested two needles (patient 1) and other patient had ingested one needle (patient 2). Both of these patients were completely asymptomatic. Abdominal examination was normal. Abdominal Xray showed the ingested needles in lower abdomen and pelvic area (Figures 1-4). Patients were advised admission and possible intervention, but both were reluctant for admission and left the hospital against our advice. Next day morning both patients presented in our out patient department with the history of passage of the needles in feces uneventfully. Confirmatory x-rays were taken showing absence of the needles in both patients.

\section{Discussion}

Treatment of foreign body ingestion involves hospitalization and close observation. Most authors agree that the majority of them will pass on their own, but the case is a different one if the ingested foreign body is a long sharp pointed object like a
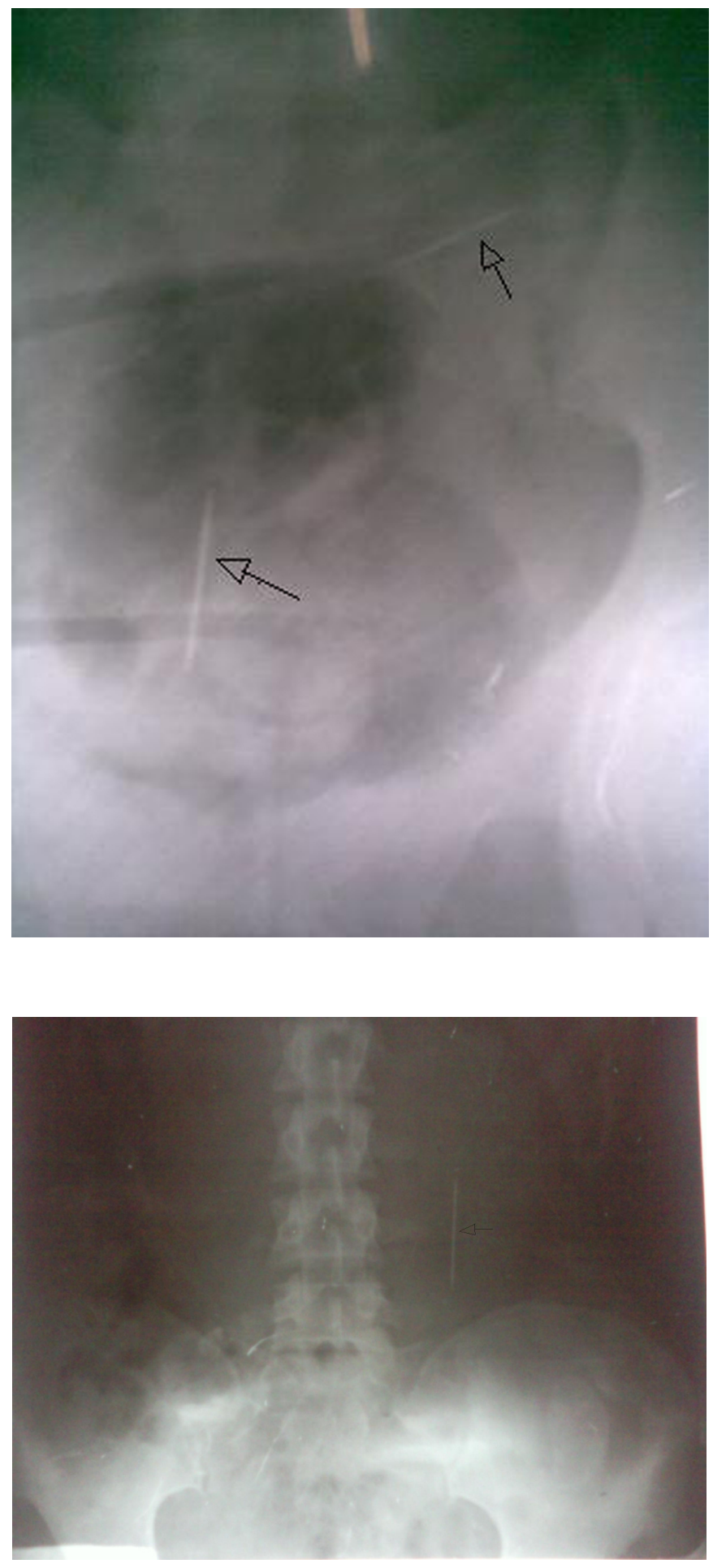

long needle.. Impaction occurs at physiological narrowings or angulations and strictures. ${ }^{3-5}$ The physiological narrowings are the cricopharyngeus, aortic arch, left main stem bronchus, lower esophageal sphincter, pylorus, ileocecal valve, and anus. The duodenal sweep is a physiological angulation. Generally, objects greater than $2 \mathrm{~cm}$ in diameter will not pass through the 

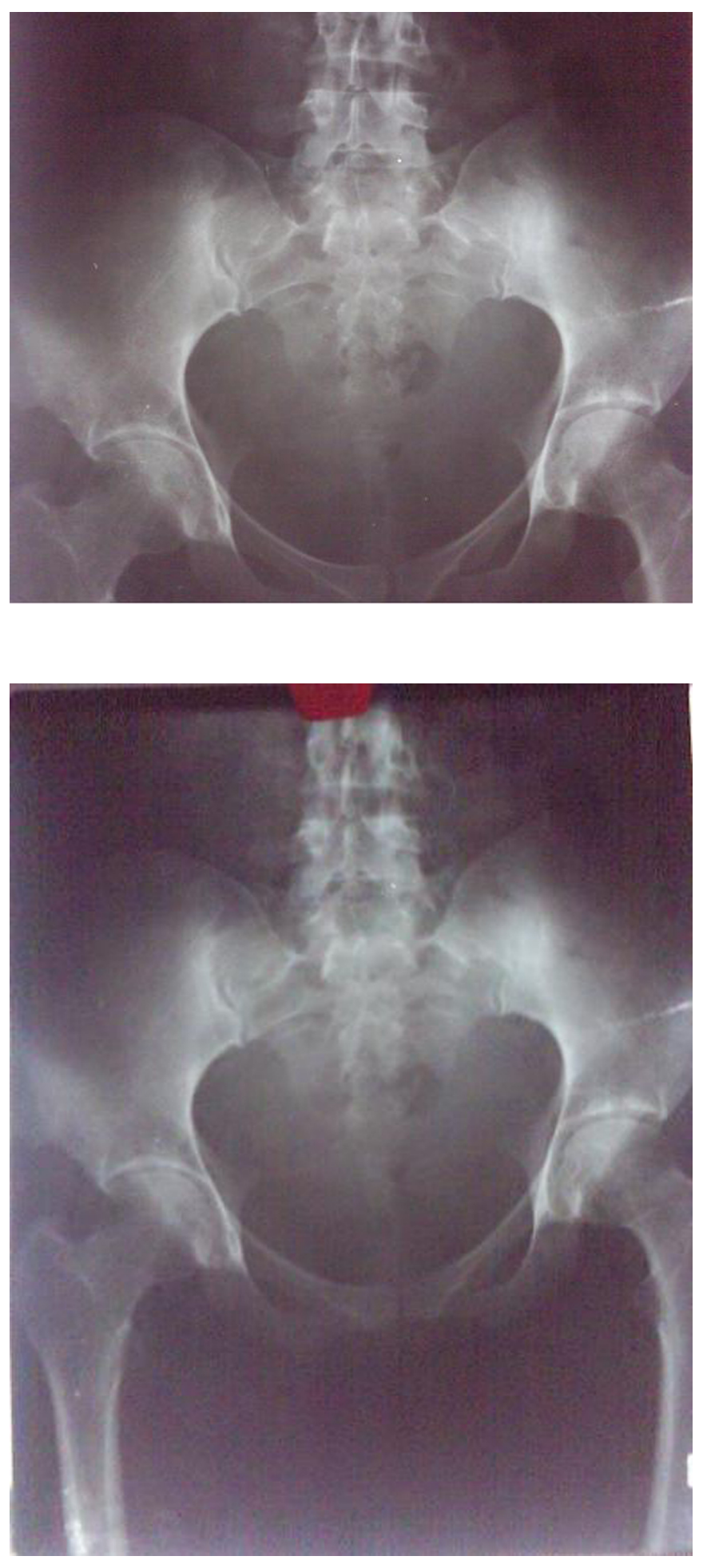

pylorus or ileocecal valve and objects longer than $5 \mathrm{~cm}$ will not pass by the duodenal sweep.

Endoscopic removal is contraindicated if the object is located above the upper esophageal sphincter or if there is clinical or radiographic evidence of perforation. Objects located proximally to the upper esophageal sphincter should be removed by an otolaryngologist. ${ }^{3-5}$ Ingested sharp-pointed objects have the highest rates of perforation, (up to 35\%) and those within the esophagus, stomach or duodenum should be removed endoscopically on an urgent basis. Surgical intervention is considered if endoscopic removal fails, if the patient develops symptoms or if the object fails to progress over 72 hours. Laparotomy should be reserved for those who develop overt acute abdomen and in whom the object cannot be endoscopically retrieved.

\section{PARWEZ SAJAD KHAN ${ }^{1}$ HUMERA HAYAT $^{2}$}

Correspondence: Dr. Parwez Sajad Khan Department of surgery Sher-i-Kashmir Institute of Medical Sciences, Medical College Hospital, Bemina Srinagar, Kashmir, India. Email: parwezsajad@yahoo.co.in

\section{References}

1. Sethi DS, Stanley RE. Migrating foreign bodies in the upper digestive tract. Ann Acad Med Singapore. 1992;21:390-3.

2. Velitchkov NG, Grigorov GI, Losanoff JE, Kjossev KT. Ingested foreign bodies of the gastrointestinal tract: retrospective analysis of 542 cases. World J Surg. 1996;20:1001-5.

3. Blaho KE, Merigian KS, Winbery SL, Park LJ, Cockrell M. Foreign body ingestion in the Emergency Department: case reports and review of treatment. J Emerg Med. 1998;16:21-6.

4. Lai AT, Chow TL, Lee DT, Kwok SP. Risk factors predicting the development of complications after foreign body ingestion. $\mathrm{Br}$ Surg. s2003;90:1531-5.

5. Weiland ST, Schurr MJ. Conservative management of ingested foreign bodies. J Gastrointest Surg. 2002;6:496-500.

\section{Congenital short pancreas}

\section{Introduction}

Pancreatic anomalies are only rarely reported, but complete agenesis of the dorsal pancreas is extremely rare. ${ }^{1}$ Partial agenesis mostly affects dorsal part, because it relies on different genes and signaling events from those of ventral pancreas. ${ }^{2}$ Our case presented with recurrent episodes of pancreatitis. Investigations showed absent body and tail of the pancreas. Patient had no evidence of chronicity in the remaining pancreas. 